\title{
CORRECTION
}

\section{Correction to: Sleep and Epilepsy: a Focused Review of Pathophysiology, Clinical Syndromes, Co-morbidities, and Therapy}

\author{
J. Layne Moore ${ }^{1,2} \cdot$ Diego Z. Carvalho ${ }^{1,3} \cdot$ Erik K. St Louis $^{1,2,3,4} \cdot$ Carl Bazil $^{5}$ \\ Published online: 13 April 2021 \\ (c) The American Society for Experimental NeuroTherapeutics, Inc. 2021, corrected publication, 2021
}

Correction to: Neurotherapeutics (2021)

https://doi.org/10.1007/s13311-021-01021-w

This erratum is to correct the spelling of the authors name.

It should be spelled as Erik K. St Louis.

The original article has been corrected.
Publisher's Note Springer Nature remains neutral with regard to jurisdictional claims in published maps and institutional affiliations.

The original article can be found online at https://doi.org/10.1007/

s13311-021-01021-w.

Erik K. St Louis

StLouis.Erik@mayo.edu

1 Mayo Clinic College of Medicine, 200 First Street SW, Rochester, MN 55905, USA

2 Departments of Neurology, Mayo Clinic, Rochester, MN, USA

3 Departments of Medicine, Mayo Clinic College of Medicine and Science, Rochester, MN, USA

4 Mayo Clinic Health System Southwest Wisconsin, La Crosse, WI, USA

5 Division of Epilepsy and Sleep, Columbia University, New York, NY, USA 